\title{
Resums
}

\section{Lluïsa Astruc}

La prosòdia dels elements externs a l'oració en català

Aquest article examina l'entonació dels constituents externs a l'oració en català. L'objectiu principal de l'article és investigar si existeix una correspondència entre forma prosòdica i funció gramatical, tal com s'ha argumentat sovint. Un altre objectiu és identificar els mecanismes que fa servir el català per marcar la independència i la dependència prosòdiques. Per tal d'acomplir aquests objectius es va dur a terme un experiment per a obtenir diverses alçades de camp tonal. Es conclou que els constituents externs no formen una categoria homogènia, ni sintàcticament ni prosòdicament, i que presenten una gran varietat de realitzacions prosòdiques. Així, les frases tipus 'va dir' són desaccentuades, les aposicions i les frases de relatiu no restrictives copien el patró entonatiu de la frase principal en una tonalitat més baixa, alguns parèntesis fan servir un camp tonal més reduït i els adverbis del tipus 'francament' no mostren cap tipus de subordinació tonal.

Paraules clau: sintaxi, entonació, constituents externs, subordinació tonal.

\section{Mercedes Cabrera Abreu; María Luisa García Lecumberri}

La manifestació del focus entonatiu en castellà peninsular

L'article presenta una anàlisi fonològica del focus entonatiu en castellà peninsular. Hom defensa que l'esglaonament descendent és un dels indicis acústics que marquen el focus en aquesta llengua. S'exploren els problemes fonològics per explicar aquest fenomen en el model mètric i autosegmental i s'ofereixen solucions alternatives seguint el model de to únic proposat per Cabrera Abreu (2000) en el marc de la fonologia de recció (tenint també en consideració altres propostes de l'autora i dels seus col-laboradors). Típicament, els elements prefocals i focals participen en relacions de legitimació que els integren en una estructura fonològica ben formada en termes d'inici i nucli respectivament dins un altre constituent major: el grup d'entonació. La realització entonativa dels elements prefocals i focals en els diferents dominis s'expliquen per la presència/absència de to associat a diferents límits de constituents. El constituent que legitima l'element focal és precedit per un grup d'entonació amb un constituent nuclear buit, fent que els límits prosòdics sense to siguin responsables de l'efecte d'esglaonament descendent observat.

Paraules clau: focus entonatiu, representacions fonològiques, esglaonament, relacions de llicència, inici, nucli, grup d'entonació, to, associació de to, límits de constituents, nucli buit. 


\section{Mariapaola D'Imperio}

Estructura tonal i punts d'inflexió del focus en italià

Aquest article investiga l'estructura tonal de l'accent focal de les oracions declaratives amb focus estret en italià de Nàpols. Les propietats formals de l'accent focal es podrien en principi analitzar de dues maneres possibles, bé com un accent tonal HL de tipus descendent o bé com un accent tonal LH de tipus ascendent. Les dues possibles anàlisis són avaluades en funció del comportament de l'accent tonal en constituents que contenen un nombre variable de mots. Els constituents focalitzats presenten una vall d'F0 que es comporta com un clar objectiu entonatiu. Aquest punt d'inflexió podria ser part també d'un accent HL o LH. Indicis tonals i temporals donen suport a la hipòtesi que es tracta d'un accent tonal ascendent. D'aquesta anàlisi se'n deriva el fet que el moviment tonal descendent final de les oracions declaratives s'ha d'analitzar com un gest tonal diferent de l'accent nuclear i que aquest es comporta de forma anàloga al to de frontera ascendent final de les oracions interrogatives.

Paraules clau: focus, accent tonal, punts d'inflexió, alineació, altura tonal, pendent tonal, italià.

\section{Gorka Elordieta}

The Spanish intonation of speakers of a Basque pitch-accent dialect

Aquest article descriu i analitza els principals aspectes de l'entonació de les oracions declaratives de l'espanyol parlat a Lekeitio. En aquesta varietat, els accents tonals es realitzen com a moviments ascendents en lloc de descendents: en això s'apropen a la varietat estàndard d'espanyol peninsular i es distingeixen de l'altra seva llengua nativa, el basc parlat a Biscaia. Les valls s'alineen abans del començament de la sílllaba accentuada, llevat dels accents que es troben en posició final de frase. Els pics s'alineen abans del final de la sílllaba accentuada (fins i tot abans en posició d'objecte directe). Al final dels subjectes, els pics mostren més desplaçament cap a la sílllaba següent. El nombre de síllabes àtones entre accents tonals també sembla afectar la posició de les valls i dels pics en algunes posicions. En posicions que no són d'objecte, les valls d'F0 s'alineen abans quan hi ha més síl-labes àtones intermèdies, i en posició final de subjecte, els pics se situen més tard quan hi ha més síl-labes àtones.

Paraules clau: entonació del castellà, accents bitonals, alineació del pic tonal.

\section{Eva Estebas-Vilaplana}

La modelització dels accents prenuclears de les declaratives en català central

L'objectiu d'aquest article és analitzar les propietats fonètiques i fonològiques dels accents prenuclears de les frases declaratives en català central amb el model mètric autosegmental d'anàlisi entonativa. Els accents prenuclears presenten un moviment ascendent, el pic del qual sol estar situat després de la síl-laba accentuada. Es consideren les següents tres possibilitats per a l'anàlisi fonològica d'aquest accent tonal: 1) un accent $\mathrm{H}^{*}$ amb desplaçament del pic, 2) un accent bitonal del tipus $\mathrm{L}^{*}+\mathrm{H}$, i 3 ) la combinació de dos tons diferents, és a dir, un accent tonal ( $\left.\mathrm{L}^{*}\right)$ més un to de frontera de mot $(\mathrm{H})$. Per saber si la presència d'una frontera de mot afecta la localització del pic, l'estudi analitza el comportament del pic tonal en mots amb diferents distribucions accentuals (aguts, plans i esdrúixols). Els resultats demostren que el pic se situa de manera sistemàtica a final de mot, independentment del nombre de síllabes posttòniques. Per tant, els 
moviments ascendents prenuclears en català central s'interpreten com la combinació d'un accent tonal $\mathrm{L}^{*}$ més un to de frontera de mot $\mathrm{H}$.

Paraules clau: accents tonals prenuclears, alineació, associació, desplaçament del pic, bitonalitat, tons de frontera de mot.

\section{Timothy L. Face}

L'entonació de les oracions declaratives en castellà: diferències entre parla de laboratori i parla espontània

Aquest estudi compara l'entonació de les oracions declaratives del castellà en la parla de laboratori i en la parla espontània. La majoria d'estudis sobre l'entonació del castellà s'han basat en la parla de laboratori, recollida a través de la lectura de frases i en un marc experimental. Encara que aquest mètode permet l'investigador de controlar molts factors, els resultats poden no ser representatius de la parla espontània. Aquest estudi examina els trets més característics de l'entonació de les oracions declaratives del castellà i comprova si aquests mateixos trets existeixen en la parla espontània. Es demostra que hi ha diferències notables entre l'entonació de les oracions declaratives. Mentre algunes diferències són de tipus menor, n’hi ha que són més significatives. Així, trobem un contrast entre el comportament dels moviments ascendents a través de la síl·laba accentuada, l'alineació dels pics tonals, l'abaixament tonal final i la desaccentuació.

Paraules clau: entonació, espanyol, to, F0, abaixament tonal, abaixament tonal final, desaccentuació, parla espontània, parla de laboratori.

\section{Sónia Frota}

L'estatus fonològic dels pics inicials de frase en portuguès europeu

Aquest article estudia el comportament fonològic dels pics inicials de frase en l'entonació del portuguès europeu. Es presenta evidència a favor de l'existència de dos tipus de pics tonals: a) un pic accentual que s'alinea sempre amb la primera síllaba accentuada de la frase; b) un pic de frase que s'alinea amb la frontera esquerra de la frase entonativa i se situa dins dels límits del mot prosòdic. El primer tipus de pic es representa fonològicament mitjançant un accent $\mathrm{H}^{*}$, mentre que el segon es representa mitjançant un to $\mathrm{H}$ amb una associació perifèrica amb la frontera esquerra de la frase entonativa i una associació secundària amb el primer mot prosòdic. Aquest lligam secundari evita que ocorrin conjuntament un accent de frase $\mathrm{H}$ i un accent tonal a l'esquerra d'un contorn entonatiu. Aquest estudi ofereix una nova explicació dels pics inicials de frase que contribueix a entendre millor les opcions d'associació possibles a l'inici d'un contorn entonatiu en portuguès.

Paraules clau: pics tonals, accent tonal, tons de frontera, alineació tonal, associació tonal.

\section{Martine Grice; Michelina Savino}

Map Tasks en italià: preguntes sobre informació coneguda, informació nova i informació accessible

Aquest article demostra que en italià de Bari hi ha una diferència entonativa entre les preguntes absolutes que pregunten sobre informació nova (classificades com a QUERY-YN en l'esquema 
de codificació de l'HCRC Map Task) i les que pregunten sobre informació ja coneguda (classificades com a CHECK en el mateix esquema de codificació). En el primer tipus de pregunta, en què el parlant creu que la informació que pregunta no és compartida pel seu interlocutor, es fa servir un accent tonal de tipus ascendent $\left(\mathrm{L}+\mathrm{H}^{*}\right)$. En canvi, en el segon tipus de pregunta, en què el parlant creu que la informació és activa en l'acte de parla, es fa servir un accent tonal de tipus descendent $\left(\mathrm{H}^{*}+\mathrm{L}\right.$ or $\left.\mathrm{H}+\mathrm{L}^{*}\right)$. Aquesta situació és més complicada per accions classificades com a CHECKS que pregunten sobre informació que ha estat mencionada abans en el discurs i els prototípics CHECKS en els quals la informació ha estat mencionada just abans en el torn de conversa. Aquestes accions, segons si es pregunta sobre informació accessible en el discurs o informació coneguda en general, presenten accents tonals ascendents i descendents. La variació entonativa es relaciona amb el grau de seguretat del parlant que l'oient donarà una resposta a la seva pregunta.

Paraules clau: entonació de l'italià, entonació interrogativa, accent tonal, accent de frontera, entonació i pragmàtica, diàleg orientat, entonació i estructura informativa, informació coneguda, informació nova, accessibilitat de la informació.

\section{José Ignacio Hualde}

Entorn de la reconstrucció de l'entonació protoromànica

Aquest article examina l'entonació de les llengües romàniques des d'un punt de vista diacrònic. Hom adopta la visió que aquesta és una àrea oberta a la investigació i que l'ús de tècniques comparativistes pot ser molt profitós per investigar l'evolució i diversificació dels patrons entonatius en les llengües romàniques. El focus d'estudi d'aquest article és l'entonació de l'occità. L'occità és una llengua pont l'estudi de la qual pot ajudar a respondre per què el sistema prosòdic del francès és tan diferent d'altres sistemes ibero- i italoromànics. L'article defensa que, atès que l'occità ha mantingut contrastos pel que fa a l'accent de mot, qualsevol tret prosòdic que trobem tant en occità com en francès és lògicament independent de la presència o absència d' accent contrastiu.

Paraules clau: occità, francès, entonació, accent, prosòdia diacrònica.

\section{Marta Payà}

La prosòdia i la pragmàtica de les insercions parentètiques en català

En aquest article es pretén analitzar el paper de la prosòdia en una estructura molt habitual, tant en la parla com en l'escriptura, però en canvi molt poc estudiada: les insercions parentètiques. A partir de diversos fets de parla en català central, amb diferents graus d'espontaneïtat, s'ha recopilat un corpus d'insercions parentètiques orals. Després d'algunes remarques sintacticosemàntiques, se n'analitzen les característiques prosòdiques següents: autonomia prosòdica, llargada, pauses, velocitat, intensitat, to i melodia. Tot i que pot ser que no sempre apareguin tots, els trets prosòdics prototípics d'una inserció parentètica en català són: autonomia prosòdica, extensió normalment breu, producció entre pauses o bé seguida de pausa, tendència a l'acceleració de la velocitat, baixada d'intensitat, producció en una tessitura més baixa que l'habitual i contorn melòdic descendent o bé, en alguns casos, ascendent. A partir de l'anàlisi del corpus, s'arriba a la conclusió que l'estructura amb final descendent és la més freqüent en la conversa espontània amb un grau alt de confiança entre els interlocutors, mentre que el patró amb final ascendent l'hem trobat sobretot en les entrevistes, en les quals el grau de coneixement entre els interlocutors és menor, els rols dels participants són desiguals i l'entrevistat construeix un discurs narratiu. Per 
això, la melodia de les insercions parentètiques podria estar relacionada amb la formalitat i amb la tipologia del discurs (en aquest cas, narratiu o dialogat). Tenint en compte les funcions discursives que exerceixen, es proposa una tipologia que les agrupa en dues funcions principals: compleció informativa i modalització.

Paraules clau: prosòdia, entonació, insercions, parèntesis, incisos, estructures parentètiques, català.

\section{Juan Manuel Sosa}

Les preguntes parcials en espanyol: variació en les configuracions tonals i significat

Aquest article descriu les configuracions tonals que poden adoptar les interrogatives parcials en espanyol i la relació entre aquestes configuracions i aspectes pragmàtics i interaccionals. Les dades de l'article provenen de fragments parla llegida i espontània de diferents varietats de l'espanyol llatinoamericà. Dos dels dialectes, el mexicà i el colombià, prefereixen els contorns de tipus ascendent en estil de lectura, mentre que en parla espontània gairebé no hi apareixen. També apareix un altre tipus de contorn ascendent en la parla espontània, que s'usa per a fer preguntes parcials confirmatòries o bé de represa: es tracta d'un contorn globalment ascendent, sense descens abans de la pujada final. La conclusió d'aquest estudi és que la configuració no marcada per a les preguntes parcials és la de tipus descendent. Això s'aplica a tots els dialectes examinats i malgrat la variació que ofereixen els contorns, que és induïda pel context pragmàtic i l'estructura informativa.

Paraules clau: prosòdia, entonació, estructura informativa, preguntes parcials, configuracions tonals, variabilitat tonal, espanyol llatinoamericà.

\section{Marina Vigário}

Prosòdia i ambigüitat estructural en portuguès europeu

Aquest article examina diferents tipus d'ambigüitat estructural en portuguès europeu. Els materials inclouen oracions amb adverbis amb diferents direccionalitats pel que fa a l'adjunció, adjunts i complements preposicionals ambigus pel que fa al nivell d'incrustació sintàctica, clàusules no restrictives amb antecedents locals i no locals, i frases de relatiu ambigües pel que fa a la seva interpretació restrictiva i no restrictiva. A banda de proporcionar una descripció prosòdica d'aquests diferents tipus d'oracions, l'article estudia la relació entre estructura prosòdica i estructura sintàctica. Es conclou que l'ambigüitat sintàctica no sempre té un correlat prosòdic, i pot ser que el correlat prosòdic també sigui opcional. A més, algunes opcions de separacions prosòdiques entre frases entonatives només són possibles en algunes interpretacions, de manera que en algunes configuracions sintàctiques especifíques no es poden inserir barreres entonatives (per exemple, entre un nucli i un complement o modificador adjacent). En tots els casos, les frases entonatives juguen un paper important per poder desfer l'ambigüitat de les oracions. Una frontera de frase entonativa després dels adverbis divisors indica adjunció a l'esquerra i entre el constituent i el grup anterior indica adjunció no local. Interpretem que aquests fets es deriven directament de les condicions intrínseques de construcció dels dominis entonatius.

Paraules clau: prosòdia, entonació, agrupació prosòdica, interfície sintaxi-fonologia, ambigüitat estructural. 